\title{
Complications of surgical treatment of cervical carcinoma
}

\section{F.S. Abrão, R.C. Breitbarg, \\ A.T. Oliveira and \\ F.A. Vasconcelos}

\author{
Departamento de Ginecologia, Hospital A.C. Camargo, \\ Fundação Antonio Prudente, 01509-010 São Paulo, SP, Brasil
}

\author{
Correspondence \\ F.S. Abrão \\ Departamento de Ginecologia \\ Hospital A.C. Camargo \\ Fundação Antonio Prudente \\ 01509-010 São Paulo, SP \\ Brasil
}

Publication supported by FAPESP.

Received March 12, 1996 Accepted October 21, 1996

\begin{abstract}
A total of 302 patients with stage Ib and IIa cervical carcinoma were submitted to radical hysterectomy and lymphadenectomy during the period from 1980 to 1994 . The morbidity rate was $37.5 \%$ and the mortality rate $0.6 \%$. The most common intraoperative complications were injuries to the great pelvic vessels and the most frequent postoperative complications involved the urinary tract. The leading causes of morbidity were urinary infection $(20.8 \%)$, bladder dysfunction $(9.2 \%)$ and ureteral fistulas $(2.9 \%)$. Although the rate of complications was high, morbidity has been decreasing over the last five years. Thus, radical hysterectomy continues to be one of the methods for the treatment of early cervical carcinoma that presents an acceptable 5year survival rate.
\end{abstract}

Key words

- Early cervical carcinoma

- Radical hysterectomy

- Surgical complications

\section{Introduction}

Cervical carcinoma has been treated by radical surgery, radiotherapy or both since the end of the last century, with each therapeutic modality presenting advantages and disadvantages (1).

The conduct followed at the Departamento de Ginecologia, Hospital A.C. Camargo, Fundação Antonio Prudente, São Paulo, for the treatment of the early stages (Ib and IIa) of the disease has been radical surgery, i.e., Wertheim Meigs operation, which consists of total abdominal hysterectomy + bilateral salpingo-oophorectomy + parametrectomy and pelvic lymphadenectomy. Because of its extent, this surgery is associated with possible complications. The proximity of the low urinary tract, anatomically related to the cervix, considerably increases the risk of complications and the development of fistulas, which attracted great attention on the part of gynecologists in the past $(2,3)$. Furthermore, the terminal portion of the digestive tract, in a position contiguous to the uterus, requires special attention during surgery. Finally, the removal of lymphatic drainage, closely related to the large vessels, which is the oncologic principle of this surgery, should be executed carefully (4).

With the improvement of pre- and postoperative care and the evolution of the surgical technique, the frequency of complications due to this surgery has been decreasing. The complications most frequently reported in the literature have been bladder dysfunction, urinary tract infections, lymphocysts and pulmonary thromboembolism (5-7).

The objective of the present study was to report the incidence and types of complica- 
Figure 1 - Age distribution of 302 patients with stage $\mathrm{lb}$ and Ila cervical cancer submitted to radical hysterectomy and lymphadenectomy. Mean age was 43 years. tions observed in our Department after radical hysterectomy.

\section{Material and Methods}

The study was based on 302 patients with cervical carcinoma in clinical stages Ib (238 cases) and IIa (64 cases) consecutively diagnosed and treated by radical hysterectomy and pelvic lymphadenectomy in our Department from 1980 to 1994 . The patients were divided into two groups, i.e., those treated from 1980 to $1988(\mathrm{~N}=152)$ and those treated from 1989 to $1994(\mathrm{~N}=150)$.

Patient age at first examination is presented in Figure 1. Mean age was 43 years. The patients were operated upon according to a routine standardized by the Department. At surgery we always explore the lymph node chains, with emphasis on the paraaortic ones. The lymphadenectomy starts at the level of the crossing of the ureter with the primitive iliac artery in the craniocaudal direction, according to the following limits: lateral to the genitofemoral nerve, medial to the ureter, inferior to the obturator nerve,

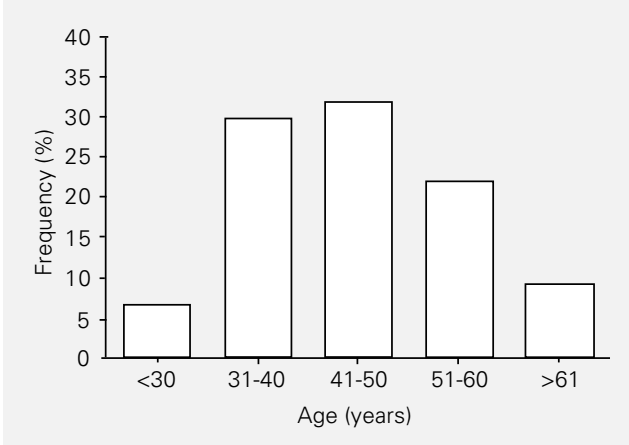

Table 1 - Radical hysterectomy patients who required blood transfusion.

\begin{tabular}{ccccc}
\hline & $\begin{array}{c}\text { No. of cases } \\
\text { operated }\end{array}$ & \multicolumn{2}{l}{ Transfused patients } & $\begin{array}{c}\text { Mean amount of } \\
\text { blood transfused (ml) }\end{array}$ \\
\cline { 3 - 4 } & No. & $(\%)$ & \\
\hline $1980-1988$ & 152 & 126 & 88.9 & 750 \\
$1989-1994$ & 150 & 57 & 38 & 600
\end{tabular}

and caudal to the circumflex vein.

The ureter was handled with care especially in relation to its peritonization, and with minimum dislocation only to permit the Wertheim maneuver, i.e., section and ligation of the pubic-vesical-cervical ligament in order to ligate and section the uterine artery.

Parametrectomy was performed as recommended by Piver et al. (8), using the socalled level III procedure. Peritonization of the pelvis was performed and a retroperitoneal siliconized drain was inserted for continuous suction.

The patients were submitted to prophylactic antibiotic treatment with $1.0 \mathrm{~g}$ cephalosporin administered $i v$ at the beginning of surgery and at 6-h intervals thereafter for 48 h. In some selected cases, treatment was continued until the removal of the bladder catheter. Patients at risk for thromboembolism were submitted to prophylactic heparinization with 5000 units administered $s c$ at 12-h intervals, starting during the preoperative period and ending on the 10th postoperative day. Blood transfusion was necessary for 126 patients $(82.9 \%)$ during the period from 1980 to 1988 , and for 57 patients (38\%) during the period from 1989 to 1994. The volume administered was $750 \mathrm{ml}$ for the first group and $600 \mathrm{ml}$ for the second (Table 1). Mean time of bladder catheterization was 8 days when the procedure was suprapubic and 9 days when the procedure was transurethral.

Histology of the surgical specimens showed the presence of squamous cell carcinoma in $84.4 \%$ of cases and of adenocarcinoma in the remaining $15.6 \%$ of cases.

After surgery, $35 \%$ of the patients were submitted to radiotherapy as complementary treatment because they were at risk for tumor recurrence.

The 5-year survival rate was $88.8 \%$ for the patients treated up to 1989 , with a $9.2 \%$ loss of follow-up.

Data were analyzed statistically by the 
chi-square test in contingency tables, with the level of significance set at $5 \%$ in all situations.

\section{Results}

Of the 302 patients investigated, 152 were treated from 1980 to 1988 and 150 from 1989 to 1994. Two postoperative deaths occurred in the first group (up to the 30th day after surgery), whereas no postoperative death occurred in the second. The two deaths were due to complications following intense bleeding during surgery. No intraoperative complications occurred in 135 of the 150 patients operated upon from 1989 to 1994 (Table 2). The leading postoperative clinical complication in this group was deep venous thrombosis, which occurred in 3 patients $(2.0 \%)$.

The occurrence of late postoperative complications is presented in Table 3 .

\section{Discussion}

Radical hysterectomy combined with pelvic lymphadenectomy, i.e., Wertheim Meigs operation, has been recommended over the last few decades for the treatment of early cervical carcinoma, stages Ib and IIa $(9,10)$. Because of the extensive nature of this surgery, a significant complication rate may occur (11). The rates reported in the literature vary from $26.7 \%$ to $50 \%(3,12,13)$, as compared to $37.5 \%$ in our series. The complications observed in our patients were minor, as indicated in Tables 2 and 3. There was no intraoperative mortality, with deaths occurring only 30 days after surgery due to excessive immediate postoperative bleeding followed by urinary fistulas. Higher death rates have been reported in the literature $(5,6,13,14)$. The same was observed with respect to the rate of intraoperative complications $(8.6 \%)$ compared to those reported by others $(3,12)$. Bleeding was the leading event $(7.4 \%)$, as also reported by others
$(15,16)$. Bleeding is caused by injuries to the great pelvic venous vessels during lymphadenectomy or by opening of the pararectal space. Bleeding may also occur when the pubic-vesical-cervical ligament is released, with injury to the internal iliac artery. Another important factor is continuous traction of the uterus which produces venous injuries in the paracolpium (17).

The mean blood volume transfused during surgery was $750 \mathrm{ml}$ for the first group and $600 \mathrm{ml}$ for the second. Other studies have reported mean values of $1724 \mathrm{ml}$ (15) and $1923 \mathrm{ml}$ (16). In our series, the blood volume transfused in the first group was greater, though not significantly so, suggesting that the surgical procedure executed at that time was more extensive, and its general results today show the same survival rate. The same applies to the results of others cited above.

The rate of urinary fistulas for the 152 patients of the first group (1980-1988) was

Table 2 - Intraoperative complications of radical hysterectomy patients.

\begin{tabular}{lcc}
\hline Type & No. of cases & $(\%)$ \\
\hline Hemorrhage & 11 & 7.38 \\
Bladder injury & 2 & 1.34 \\
Intestinal injury & 2 & 1.34
\end{tabular}

Table 3 - Postoperative complications of radical hysterectomy patients.

\begin{tabular}{|c|c|c|c|c|c|}
\hline & \multicolumn{2}{|c|}{$\begin{array}{l}1980-1988 \\
\text { (152 cases) }\end{array}$} & \multicolumn{2}{|c|}{$\begin{array}{c}1989-1994 \\
\text { (150 cases) }\end{array}$} & \multirow{2}{*}{$\frac{\begin{array}{c}\text { Total } \\
\text { (302 cases) }\end{array}}{(\%)}$} \\
\hline & No. & $(\%)$ & No. & $(\%)$ & \\
\hline Urinary infection & 35 & 23.0 & 28 & 18.4 & 20.8 \\
\hline Bladder dysfunction & 17 & 11.3 & 11 & 7.3 & 9.2 \\
\hline Ureterovaginal fistula & 7 & 4.6 & 2 & 1.32 & 2.9 \\
\hline Vesicovaginal fistula & 1 & 0.66 & 1 & 0.66 & 0.6 \\
\hline Incisional hernia & 3 & 2.0 & 5 & 3.65 & 2.6 \\
\hline Lymphocyst & 2 & 1.3 & 4 & 2.66 & 1.9 \\
\hline
\end{tabular}


$5.2 \%$ ( 8 cases), a value similar to those reported in recent studies $(2,12)$. The rate of urinary fistulas for the 150 patients in the second group (1989-1994) was 1.9\% (3 cases). The incidence of urinary fistulas has decreased considerably over the last few years, ranging from $1 \%$ to values as high as $30 \%$ in the past $(18,19)$, whereas more recent studies have reported rates of $2.4 \%$ (16). We describe a series of procedures that can minimize the incidence of urinary fistulas, such as careful and delicate dissection of the ureter, drainage of the retroperitoneal space with a siliconized continuous-aspiration drain, the prophylactic use of antibiotics and the use of a suprapubic bladder catheter for about 12 days.

We believe that the surgical performance of staff members trained in gynecologic oncology over the last five years has been more uniform, leading to much lower rates of this complication compared to the classical studies of Meigs and Wertheim (20,21).

The most frequent complication reported in the literature is bladder dysfunction, occurring in 10 to $50 \%$ of cases $(5,11,22)$. In our series, bladder dysfunction occurred in 17 patients of the first group (11.3\%) and in 11 patients of the second $(7.3 \%)$. This decrease in the rate of bladder dysfunction may have been due to smaller injuries to the nervous plexuses related to the bladder, which were extensively sectioned in the past. Most of the cases regressed spontaneously within a period of as long as 40 days, the major obstacle being transurethral catheterization that led to an increased rate of urinary infection (4).

Another complication reported by several investigators is the onset of lymphocysts (3). The use of continuous retroperitoneal suction with a vacuum silicon drain after pelvic lymphadenectomy reduces the accumulation of serum and blood secretion in this space, with a marked reduction of the occurrence of fibrosis and infection. In no case was it necessary to perform a new laparotomy to resolve this complication.

Significant changes have occurred over the last decades with respect to the indication of radical Wertheim Meigs operation. Age and obesity have become relative rather than formal contraindications. Extensive para-aortic retroperitoneal lymphadenectomy has also proved to be unnecessary in routine cases. Our experience (1) has demonstrated that the complication and morbidity rates have been decreasing because of the standardization of the surgical procedure and of the training of gynecologic oncologists. Radical hysterectomy with pelvic lymphadenectomy has been accepted as an adequate method for the treatment of cervical carcinoma (1), with satisfactory five-year survival rates. 


\section{References}

1. Abrão FS (1995). Tratamento cirúrgico do câncer do colo do útero. In: Abrão FS (Editor), Tratado de Oncologia Genital e Mamária. Roca, São Paulo, 289-303.

2. Riss $P$, Neunteuful $W \&$ Janish $H$ (1988). Wertheim radical hysterectomy 1921 . 1986: changes in urologic complications. Archives of Gynecology and Obstetrics, 243: 249-253.

3. Symmonds RE (1966). Morbidity and complications of radical hysterectomy and pelvic lymph node dissection. American Journal of Obstetrics and Gynecology, 94: 663672.

4. Abrão FS \& Coelho FRG (1995). Princípios e cuidados gerais em cirurgia oncológica ginecológica. In: Abrão FS (Editor), Tratado de Oncologia Genital e Mamária. Roca, São Paulo, 129-139.

5. DiSaia PJ \& Creasman WT (1989). Clinical Gynecologic Oncology. C.V. Mosby, New York, 90-93.

6. Ayhan A, Tuncer ZS \& Yarali H (1991). Complications of radical hysterectomy in women with early stage cervical cancer: clinical analysis of 270 cases. European Journal of Surgical Oncology, 17: 492-494.

7. Carvalho JP, Souen JS, Carramão SS, Yeu WL \& Pinotti JA (1994). Wertheim-Meigs radical hysterectomy. Revista Paulista de Medicina, 112: 539-542.

8. Piver MS, Rutledge F \& Smith JP (1974). Five classes of extended hysterectomy of women with cervical cancer. Obstetrics and Gynecology, 44: 265-272.
9. Abrão FS (1988). Associações terapêuticas no câncer do colo do útero. In: Pinotti JA \& Teixeira LC (Editors), Oncologia Ginecológica e Mamária. UNICAMP, Campinas.

10. Abrão FS \& Abrão MS (1992). Aspectos atuais do tratamento do câncer do colo do útero. Ginecologia e Obstetrícia Atualizadas, 2: 21-26.

11. Abrão FS, Jales AFC, Marziona F, Coelho FRG \& Breitbarg RC (1992). Tratamento cirúrgico do câncer do colo do útero. Prevenção das complicações. Femina, 20: 292-296.

12. Timmer PR, Aalders JG \& Bouma J (1984). Radical surgery after preoperative intracavitary radiotherapy for stage IB and IIA carcinoma of the uterine cervix. Gynecologic Oncology, 18: 206-212.

13. Zander J, Baltzer J, Lake KJ, Ober KG \& Kaufmann C (1981). Carcinoma of the cervix: an attempt to individualize treatment. American Journal of Obstetrics and Gynecology, 139: 75-81.

14. Mattingly RF \& Thompson JD (1985). Te Linde's Operative Gynecology. J.B. Lippincott, Philadelphia, 813-817.

15. Hervy $E$, Averette MD \& Nguyen HN (1993). Radical hysterectomy for invasive cervical cancer. Cancer, 71: 1422-1437.

16. Lee Y-N, Wang KL \& Lin M-H (1989). Radical hysterectomy with pelvic lymph node dissection for treatment of cervical cancer: a clinical review of 954 cases. Gynecologic Oncology, 32: 135-142.
17. Kobayashi T (1961). Abdominal Radical Hysterectomy with Pelvic Lymphadenectomy for Cancer of Cervix. 2nd edn. Nanzando, Tokyo, 86-329.

18. Falk V, Lundgren N, Quarfordt L \& Arstrom K (1982). Primary surgical treatment of carcinoma stage I of the uterine cervix. Acta Obstetrica et Gynaecologica Scandinavica, 61: 481-486.

19. Novak F (1956). Procedure for the reduction of the number of ureter-vaginal fistulas after Wertheim's operation. American Journal of Obstetrics and Gynecology, 72: 506-510.

20. Meigs JV (1951). Radical hysterectomy with bilateral pelvic lymph node dissections: a report of 100 patients operated on five or more years ago. American Journal of Obstetrics and Gynecology, 62: 854870.

21. Wertheim E (1912). The extended abdominal operation for carcinoma uteri (based on 500 operative cases). American Journal of Obstetrics and Gynecology, 66: 169-232.

22. Underwood PB, Wilson WC, Kreutner $A$ Miller MC \& Murphy E (1979). Radical hysterectomy: a critical review of twentytwo years' experience. American Journal of Obstetrics and Gynecology, 134: 889898 